\title{
EKSPERIMENTASI MODEL PEMBELAJARAN PBL, JIGSAW DAN STAD TERHADAP PEMAHAMAN KONSEP DAN PEMECAHAN MASALAH MATEMATIKA DITINJAU DARI ADVERSITY QUOTIENT (AQ) SISWA
}

\author{
Lia Ariati' ${ }^{1}$ Budiyono $^{2}$, Dewi Retno Sari Saputro ${ }^{3}$ \\ ${ }^{1,2,3}$ Prodi Magister Pendidikan Matematika, FKIP Universitas Sebelas Maret Surakarta
}

\begin{abstract}
The aim of this research was to know the effect of the Problem Based Learning (PBL), Jigsaw, and Students Teams Achievement Divisions (STAD) to the mathematics conceptual understanding and problem solving viewed from students Adversity Quotient (AQ). The type of this research was quasi-experimental with factorial design $3 \times 3$. The population was all the students of grade XI IPS SMA/MA in Wonogiri on the second semester of 2014/2015 academic year. The sample of this research consisted of 224 students. The instruments that used to collect the data were early ability test, conceptual understanding test, problem solving test, and questionnaires Adversity Quotient of students. Data were analyzed using unbalanced two ways multivariate analysis of variance with a significance level $\alpha=5 \%$. The results of the research were as follows. (1)Students who were subjected to the PBL learning model have a better conceptual understanding than with the learning model of Jigsaw and STAD while students were subjected to the learning model of Jigsaw have a better conceptual understanding than with the learning model of STAD. (b) Students who were subjected to the PBL learning model have the same problem solving as students with the learning model of Jigsaw but it have better than with the learning model of STAD while students with Jigsaw learning models have the same problem solving as students with learning model of STAD (2)Students with high AQ have better conceptual understanding and problem solving than students with medium and low AQ, and the students with medium AQ were better than low AQ. (3)(a) In learning model of PBL and Jigsaw, students with high AQ have the same conceptual understanding as medium $\mathrm{AQ}$ but better than low $\mathrm{AQ}$, and students with medium $\mathrm{AQ}$ have a better conceptual understanding than low AQ while in learning model of STAD, students with high AQ have a better conceptual understanding than students with medium and low $\mathrm{AQ}$, and the students with medium $\mathrm{AQ}$ were better than low AQ. (b) In learning model of PBL, Jigsaw and STAD, students who have high AQ have better problem solving than students who have students with medium and low $\mathrm{AQ}$, and students with medium AQ have a better problem solving than students with low AQ. (4)(a) For high and low AQ, students were subjected to the PBL learning model have the same conceptual understanding as students who were subjected to the learning model of Jigsaw and STAD while for medium AQ, students who were subjected to the learning model of PBL have the same conceptual understanding as students who were subjected to the learning model Jigsaw but better than STAD and students who were subjected to the learning model of Jigsaw have a better conceptual understanding than students who were subjected to the learning model of STAD. (b) In each AQ, students with the PBL learning model have the same problem solving as students with Jigsaw learning model but better than STAD learning model, and students with Jigsaw learning model have a better problem solving than students of STAD learning model.
\end{abstract} Keywords : PBL, Jigsaw, STAD, AQ, conceptual understanding, problem solving.

\section{PENDAHULUAN}

Kualitas pendidikan matematika di Indonesia dipengaruhi oleh kompetensi dalam mempelajari matematika. Giganti $(2007,15)$ menyatakan bahwa, "There are three parts to learning mathematics: skills, concepts, and problem solving,". Berdasarkan pendapat tersebut ada tiga bagian penting untuk mempelajari matematika yaitu kterampilan, konsep 
dan pemecahan masalah. Ketiga hal ini merupakan komponen pokok yang mempengaruhi kompetensi seseorang dalam mempelajari matematika. Kilpatrick dalam Kaasila (2009: 249) menyebutkan, "The five strands of mathematical proficiency are (a) conceptual understanding; (b) procedural fluency; (c) strategic competence; (d) adaptive reasoning; (e) productive disposition,". Pendapat ini mengemukakan bahwa ada lima keahlian matematika yang harus dikuasai seseorang. Dengan kata lain seseorang akan berhasil dalam mempelajari matematika jika mempunyai lima kompetensi tersebut. Dari pendapat-pendapat ini pemahaman konsep (conceptual understanding) dan pemecahan masalah (problem solving) merupakan dua hal yang dapat mempengaruhi kualitas pendidikan matematika.

Selanjutnya Kaasila (2009: 249-250) menyebutkan bahwa, "Conceptual understanding refers to an integrated grasp of mathematical ideas. Students with conceptual understanding organize their ideas into a coherent whole. Conceptual understanding also makes it easier to remember facts because they can be reconstructed,". Hal ini bermakna bahwa pemahaman konsep terkait erat dengan pemahaman ide-ide matematika. Dengan pemahaman konsep siswa akan mengorganisasi ide-ide mereka secara utuh sehingga akan membuatnya mudah untuk memahami matematika itu sendiri. Untuk itu kegiatan belajar mengajar yang tidak memperhatikan pentingnya pemahaman konsep siswa menyebabkan kesulitan belajar.

Lebih lanjut NCTM (2010: 1) menyebutkan bahwa "Problem solving plays an important role in mathematics, ". Pemecahan masalah memainkan peran penting dalam matematika. Hal ini juga disetujui oleh Giganti (2007: 15) yang mengemukakan, "Problem solving is important because it requires us to combine skills and concepts in order to deal with specific mathematical situation,". Pemecahan masalah itu penting untuk mengaitkan keterampilan dan konsep dalam matematika. Untuk itu kurangnya kemampuan pemecahan masalah dalam matematika juga dapat menyebabkan kesulitan belajar. Adanya kesulitan dalam pembelajaran matematika akan menyebabkan kualitas pendidikan matematika pun juga akan rendah.

Salah satu materi yang diperoleh siswa kelas XI semester genap Sekolah Menengah Atas (SMA) adalah Turunan Fungsi. Data PAMER UN 2014 menunjukkan bahwa daya serap materi ini di Kabupaten Wonogiri masih tergolong rendah. Daya serap siswa SMA/MA di Kabupaten Wonogiri pada materi Turunan Fungsi dengan indikator menentukan nilai turunan pertama suatu fungsi aljabar berderajat tiga sebesar 56,44\%. Hal ini masih di bawah daya serap provinsi $(70,61 \%)$ maupun nasional $(62,96 \%)$ untuk indikator yang sama. Indikator lain yaitu menyelesaikan masalah yang berkaitan dengan nilai ekstrim (nilai maksimum/minimum) menggunakan konsep turunan. Siswa SMA/MA 
di Kabupaten Wonogiri untuk indikator tersebut memiliki daya serap sebesar 34,79\%. Hal ini juga masih di bawah daya serap provinsi $(39,69 \%)$ maupun nasional $(45,11 \%)$. Kedua indikator kemampuan yang diuji tersebut terkait pada pemahaman konsep dan pemecahan masalah. Itu berarti pemahaman konsep dan pemecahan masalah pada materi turunan fungsi di Kabupaten Wonogiri masih rendah. Hal ini mengindikasikan bahwa terdapat masalah pada materi Turunan Fungsi yang perlu untuk dikaji lebih lanjut.

Keberhasilan belajar dipengaruhi oleh berbagai faktor, salah satunya model pembelajaran yang digunakan guru dalam menyampaikan materi kurang tepat. Selama ini guru masih menggunakan model pembelajaran yang masih didominasi guru. Guru berbicara atau menjelaskan sedangkan siswa hanya duduk mendengarkan, meniru polapola yang diberikan guru, mencontoh cara-cara guru menyelesaikan soal-soal. Interaksi dua arah antara siswa dengan guru atau siswa dengan siswa jarang terjadi yang akhirnya membuat siswa menjadi pasif. Kondisi semacam ini mengakibatkan pembelajaran matematika kurang menarik dan penguasaan siswa terhadap materi pelajaran kurang optimal.

Suatu model pembelajaran yang lebih menempatkan siswa sebagai pusat pembelajaran diperlukan untuk meningkatkan penguasaan matematika siswa terutama dalam hal pemahaman konsep dan pemecahan masalah. Model pembelajaran yang dapat digunakan yaitu model pembelajaran Problem Based Learning ( $P B L$ ) dan kooperatif. Model pembelajaran ini lebih menekankan pada kegiatan atau aktivitas siswa dalam mengembangkan sendiri pengetahuan-pengetahuannya serta menentukan lingkungan belajar yang mendukungnya.

Problem Based Learning $(P B L)$ adalah salah satu model pembelajaran yang diawali dengan orientasi masalah dalam kehidupan nyata, kemudian dari masalah ini siswa dirangsang untuk mempelajari masalah ini berdasarkan pengetahuan dan pengalaman baru. Seperti yang dikemukakan oleh Wood dalam Masek (2012: 3) bahwa, " $P B L$ pedagogy, promotes learning through the concept of 'learning by doing', which creates an opportunity for students to learn by experiencing the process of problem solving,". Dalam PBL guru tidak menyampaikan banyak informasi kepada siswa, tetapi siswa diharapkan dapat mengembangkan pemikiran mereka. PBL dirancang untuk membantu siswa mengembangkan keterampilan berpikir, menyelesaikan masalah, belajar menjadi pembelajar yang independen serta mandiri. Berbagai kegiatan PBL yang menuntut keaktifan siswa tersebut memungkinkan mereka untuk lebih mudah mempelajari dan menguasai pengetahuan dibandingkan dengan pembelajaran yang dilakukan dalam suasana langsung, seperti yang ditulis Chamberlin \& Moon (2008: 87) bahwa, 
"Knowledge learned in PBL is likely to be transferred more easily than knowledge learned in a traditional setting. Moreover, in PBL, mathematics instructors serving as metacognitive coaches specifically create opportunities for students to see self-directed learning modeled so they understand what is required to foster it".

Hal ini sejalan dengan yang ditulis oleh Attle \& Baker (2007: 79) bahwa,

"PBL can enhance both team and individual outcomes. In PBL teams, students who may not be at the top of their class based on traditional measures of academic accomplishment have the opportunity to make meaningful contributions to the team, such as organizing tasks, managing conflicts, negotiating agreements, and facilitating interpersonal communication".

Pernyataan tersebut bermakna PBL dapat meningkatkan hasil kelompok dan individu. Dalam kelompok PBL, siswa yang mungkin bukan siswa terbaik di kelasnya akan mempunyai kesempatan untuk membuat sumbangan yang berarti untuk kelompoknya, seperti mengorganisasikan tugas-tugas, mengatur konflik, merundingkan persetujuan, dan memudahkan komunikasi antar-perseorangan.

Pembelajaran kooperatif adalah model pembelajaran yang menempatkan beberapa siswa dalam kelompok kecil dan memberikan mereka sebuah atau beberapa tugas. Ozkan (2010:6) menyebutkan bahwa, "Cooperative learning is a classroom learning approach which is used to motivation and retention, to help students to develop positive thoght about themselves and their friends, to develop student's ability to solve problems and think critically, and to encourage th students on coopertive social skills". Dalam kajian Ozkan, pembelajaran kooperatif adalah pendekatan belajar di dalam kelas yang digunakan untuk memotivasi dan daya ingat, untuk membantu siswa untuk mengembangkan pikiran positif tentang diri mereka dan teman-teman mereka, untuk mengembangkan kemampuan siswa memecahkan masalah berpikir kritis, dan untuk mendorong siswa pada keterampilan sosial bekerjasama. Model pembelajaran Jigsaw dan model pembelajaran Student Team Achievement Division (STAD), merupakan contoh dari pembelajaran kooperatif.

Model pembelajaran kooperatif tipe Jigsaw merupakan pembelajaran yang diawali dengan tugas membaca/mempelajari bahan ajar yang berbeda-beda dalam satu kelompok lalu anggota kelompok dipecah dan dikelompokkan menurut bahan ajar yang didapat. Dalam kelompok tersebut, siswa berdiskusi terkait bahan ajarnya setelah itu kembali ke kelompok awal dan menjelaskan ke anggota yang lain terkait tugasnya kemudian siswa diberi kuis tentang seluruh bahan ajar, dan skor kuis tersebut menjadi skor kelompok.

Sementara itu model pembelajaran Student Team Achievement Division (STAD) merupakan model pembelajaran kooperatif yang paling sederhana. Model ini membagi siswa atas kelompok-kelompok heterogen dan kemudian dalam kelompok-kelompok 
tersebut siswa berdiskusi untuk mempelajari suatu materi. Langkah-langkah yang dikemukakan Slavin (2005:143) yaitu Presentasi kelas, Tim, Kuis, dan Skor.

Pencapaian prestasi belajar yang optimal selain dipengaruhi oleh penggunaan model pembelajaran yang tepat dapat juga dipengaruhi oleh faktor-faktor interpersonal siswa. Salah satu faktor tersebut adalah Adversity Quotient (AQ) masing-masing siswa dalam mengadapi masalah pada mata pelajaran matematika. AQ merupakan kecerdasan seseorang dalam menghadapi rintangan atau kesulitan secara teratur (Stoltz, 2000: 9). Stoltz mengelompokkan orang dalam 3 kategori $\mathrm{AQ}$, yaitu: quitter (AQ rendah), camper (AQ sedang), dan climber (AQ tinggi). Quitters merupakan kelompok orang yang kurang memiliki kemauan untuk menerima tantangan dalam hidupnya. Campers merupakan kelompok orang yang sudah memiliki kemauan untuk berusaha menghadapi masalah dan tantangan yang ada, namun mereka berhenti karena merasa sudah tidak mampu lagi. Climbers merupakan kelompok orang yang memilih untuk terus bertahan untuk berjuang menghadapi berbagai macam hal yang akan terus menerjang, baik itu dapat berupa masalah, tantangan, hambatan, serta hal - hal lain.

Tingginya AQ siswa memungkinkan pada tingginya pemahaman konsep dan pemecahan masalah matematika. Sebaliknya AQ siswa yang rendah memungkinkan rendahnya pemahaman konsep dan pemecahan masalah matematika siswa. Ofodu (2009:209-213) menjelaskan bahwa ketidaksesuaian antara model pembelajaran yang dipakai guru dengan AQ siswa terlihat jelas dalam proses pembelajaran di sekolah. Permasalahan ini sangat dirasakan oleh siswa dengan AQ sedang dan rendah, dimana siswa tersebut cenderung acuh dalam pembelajaran jika model pembelajaran yang digunakan tidak memberi kesempatan mereka untuk ikut berusaha memecahkan masalah yang ada. Jadi dimungkinkan adanya kaitan atau interaksi model pembelajaran dengan AQ siswa.

Tujuan dari penelitian ini untuk mengetahui perbedaan efek antara PBL, Jigsaw, dan STAD pada pemahaman konsep dan pemecahan masalah matematika ditinjau dari AQ siswa dimana kategori AQ terdiri dari tinggi, sedang, dan rendah.

\section{METODE PENELITIAN}

Penelitian ini dilaksanakan di SMA/MA yang ada di Kabupaten Wonogiri. Jenis penelitian yang digunakan yaitu penelitian eksperimental semu dengan variabel bebas model pembelajaran dan AQ serta variabel terikat pemahaman konsep dan pemecahan masalah matematika siswa. Populasi dalam penelitian ini adalah seluruh siswa kelas XI SMA/MA jurusan IPS se-Kabupaten Wonogiri tahun pelajaran 2014/2015 yang menggunakan kurikulum KTSP. Sampel diambil menggunakan teknik stratified cluster 
random sampling, maka terpilih sampel SMA Negeri 3 Wonogiri (kategori tinggi), SMA Negeri 1 Slogohimo (kategori sedang), dan SMA Negeri 1 Sidoharjo (kategori rendah).

Metode pengumpulan data penelitian meliputi metode dokumentasi, angket dan tes. Instrumen penelitian yang digunakan meliputi tes kemampuan awal pemahamn konsep dan pemecahan masalah, tes pemahaman konsep, tes pemecahan masalah dan angket AQ. Sebelum melakukan eksperimen, dilakukan uji keseimbangan terhadap kemampuan awal siswa menggunakan Multivariate Analysis of Variance (MANOVA) satu jalur yang sebelumnya diuji terlebih dahulu dengan uji normalitas multivariat dan uji kesamaan variansi dan kovariansi. Uji hipotesis dilakukan menggunakan uji Two-Way MANOVA dengan desain faktorial $3 \times 3$. Jika hasil analisis variansi menunjukkan bahwa $H_{0}$ ditolak maka menganjurkan dilakukan uji lanjut yaitu uji Analysis of Variance (ANOVA). Apabila $H_{0}$ masih ditolak, dilanjutkan kembali menggunakan uji komparasi ganda menggunakan metode Scheffe'.

\section{HASIL PENELITIAN DAN PEMBAHASAN}

Hasil uji prasyarat menyimpulkan bahwa semua sampel berasal dari populasi yang berdistribusi normal dan populasi mempunyai matriks variansi dan kovariansi yang sama untuk MANOVA serta variansi yang sama untuk ANOVA. Hasil uji keseimbangan dilakukan untuk mengetahui apakah populasi ketiga kelompok pembelajaran PBL, Jigsaw dan STAD mempunyai kemampuan matematika yang sama. Berdasarkan hasil uji keseimbangan, disimpulkan bahwa sampel dari populasi PBL, Jigsaw dan STAD dalam keadaan seimbang. Selanjutnya, dilakukan uji hipotesis dan hasil pengujian hipotesis disajikan pada Tabel 1.

Tabel 1 Rangkuman Uji MANOVA Dua Jalan Sel Tak Sama

\begin{tabular}{|c|c|c|c|c|c|}
\hline Sumber & \multicolumn{2}{|c|}{ Matriks SSCP } & $F_{\text {obs }}$ & $F_{\text {tabel }}$ & Keputusan \\
\hline Faktor A (Model & {$[1673,0993$} & 1538,2438 & 7,1027 & $F_{(0,05 ; 4,440)}=$ & $H_{0}$ ditolak \\
\hline Pembelajaran) & {$[1538,2438$} & $1433,3285]$ & & 2,392 & \\
\hline Faktor B & {$[12841,0806$} & $11226,962]$ & 46,077 & $F_{(0,05 ; 4,440)}=$ & $H_{0}$ ditolak \\
\hline (AQ) & [ 11226,962 & 9861,6237] & & 2,392 & \\
\hline $\mathrm{AB}$ & {$[677,6008$} & $577,8356]$ & 2,0135 & $F_{(0,05 ; 8,440)}=$ & $H_{0}$ ditolak \\
\hline (Interaksi) & {$[577,8356$} & 834,1595] & & 1,959 & \\
\hline Residual & {$[12334,91$} & $10764,26]$ & - & 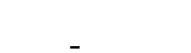 & \\
\hline (error) & [10764,26 & 25960,64] & & & \\
\hline Total & {$[27526,69$} & 24107,31] & & - & - \\
\hline (corrected) & 24107,31 & 38089,75] & 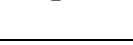 & 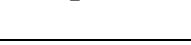 & 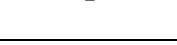 \\
\hline
\end{tabular}

Hasil uji Two-Way MANOVA tersebut dengan $F_{\alpha}=2,393$, pada taraf signifikansi $5 \%$ pada model pembelajaran dan AQ menghasilkan $F_{o b s}>F_{\alpha}$, yaitu berturut-turut $F_{o b s}=$

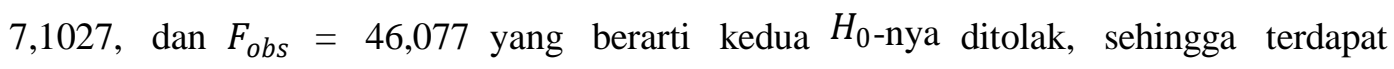
perbedaan efek model pembelajaran dan efek AQ terhadap pemahaman konsep dan 
pemecahan masalah matematika siswa. Pada interaksi, diperoleh $F_{o b s}=2,0135$ dan $F_{\alpha}=$ 1,96 pada taraf signifikansi 5\%, maka $H_{0}$ ditolak. Jadi terdapat interaksi antara model pembelajaran dan AQ terhadap pemahaman konsep dan pemecahan masalah matematika siswa.

Setelah itu dilakukan uji lanjut Two-Way ANOVA, untuk melihat apakah ada perbedaan pada masing-masing variabel terikat yaitu pemahaman konsep dan pemecahan masalah. Rangkuman uji lanjut disajikan pada Tabel 2.

Tabel 2 Rangkuman Uji Lanjut Anava Dua Jalan Sel Tak Sama

\begin{tabular}{|c|c|c|c|c|c|c|c|}
\hline $\begin{array}{l}\text { Variabel } \\
\text { Terikat }\end{array}$ & Sumber & $\mathrm{JK}$ & $d k$ & RK & $F_{o b s}$ & $F_{\alpha}$ & Keputusan \\
\hline \multirow{5}{*}{$\begin{array}{l}\text { Pemahaman } \\
\text { konsep }\end{array}$} & $\begin{array}{l}\text { Faktor A } \\
\text { (Model } \\
\text { Pembelajaran) }\end{array}$ & 1676,2 & 2 & 838,1 & 14,61 & 3.04 & $H_{0}$ ditolak \\
\hline & Faktor B (AQ) & 13844,6 & 2 & 6922,3 & 120,66 & 3.04 & $H_{0}$ ditolak \\
\hline & Interaksi & 683,9 & 4 & 170,9 & 2,98 & 2.41 & $H_{0}$ ditolak \\
\hline & $\begin{array}{l}\text { Residual } \\
\text { (error) }\end{array}$ & 12334,9 & 215 & 57,4 & - & - & - \\
\hline & Total & 28539,7 & 223 & - & - & - & - \\
\hline \multirow{3}{*}{$\begin{array}{l}\text { Pemecahan } \\
\text { Masalah }\end{array}$} & $\begin{array}{l}\text { Faktor A } \\
\text { (Model } \\
\text { Pembelajaran) }\end{array}$ & 1440,9 & 2 & 720,4 & 5,97 & 3.04 & $H_{0}$ ditolak \\
\hline & Faktor B (AQ) & 10612,6 & 2 & 5306,3 & 43,95 & 3.04 & \multirow{2}{*}{$\begin{array}{c}H_{0} \text { ditolak } \\
H_{0} \text { tidak } \\
\text { ditolak } \\
\end{array}$} \\
\hline & Interaksi & 904,20 & 4 & 226,05 & 1,87 & 2.41 & \\
\hline
\end{tabular}

Berdasarkan uji lanjut anava dua jalan sel tak sama pada Tabel 2 disimpulkan bahwa:(1) terdapat perbedaan efek model pembelajaran terhadap pemahaman konsep maupun pemecahan masalah siswa, (2) terdapat perbedaan efek AQ terhadap pemahaman konsep maupun pemecahan masalah siswa, (3) terdapat interaksi antara model pembelajaran dan AQ terhadap pemahaman konsep. Untuk melihat model pembelajaran dan AQ manakah yang lebih baik pada masing-masing variabel terikat maka dilakukan uji komparasi ganda. Akan tetapi hasil perhitungan pada Tabel 2, terlihat bahwa pada variabel terikat pemecahan masalah terdapat satu hipotesis yang tidak ditolak, sehingga tidak perlu dilakukan uji komparasi ganda. Rangkuman rerata nilai pemahaman konsep dan pemecahan masalah disajikan pada Tabel 3.

Tabel 3. Rerata Antar Sel dan Rerata Marginal

\begin{tabular}{|c|c|c|c|c|c|c|c|c|}
\hline \multirow{3}{*}{$\begin{array}{c}\text { Model } \\
\text { Pembelajaran }\end{array}$} & \multicolumn{6}{|c|}{ Adversity Quotient } & \multicolumn{2}{|c|}{ Rerata Marginal } \\
\hline & \multicolumn{2}{|c|}{ Tinggi } & \multicolumn{2}{|c|}{ Sedang } & \multicolumn{2}{|c|}{ Rendah } & & \\
\hline & $Y_{1}$ & $\mathrm{Y}_{2}$ & $Y_{1}$ & $\mathrm{Y}_{2}$ & $Y_{1}$ & $\mathrm{Y}_{2}$ & $Y_{1}$ & $Y_{2}$ \\
\hline PBL & 73,04 & 72,46 & 67,59 & 65,86 & 55,60 & & 66,10 & 66,52 \\
\hline Jigsaw &, 91 & 70, & 63,14 & 63,25 & 54,75 & & & 63,17 \\
\hline STAD & & 71, & 57,80 & 59,77 & 46,91 & 48 & 58,64 & 59,95 \\
\hline Rerata Marginal & 71,83 & 71,76 & 62,78 & 62,92 & 52,31 & 54,52 & & \\
\hline
\end{tabular}


Uji komparasi ganda menggunakan metode Scheffe'. Adapun rangkuman uji komparasi ganda antar baris pada masing-masing variabel terikat, uji komparasi ganda antar baris dan antar kolom pada masing-masing variabel terikat disajikan pada pada Tabel 4 dan Tabel 5.

Tabel 4 Rangkuman Hasil Uji Komparasi Ganda Antar Baris

\begin{tabular}{|c|c|c|c|c|c|}
\hline $\begin{array}{l}\text { Variabel } \\
\text { Terikat }\end{array}$ & $H_{0}$ & $F_{o b s}$ & $F_{(0,05 ; 2,215)}$ & Keputusan Uji & Kesimpulan \\
\hline Pemahaman & $\mu_{11} \bullet=\mu_{12} \bullet$ & 6,8354 & 6,0757 & $H_{0}$ ditolak & $\mu_{11 \bullet} \neq \mu_{12} \bullet$ \\
\hline kons & $\mu_{11} \bullet=\mu_{13}$ • & 36,0 & & $H_{0}$ & $\mu_{11} \bullet \neq \mu_{13} \bullet$ \\
\hline mate & $\mu_{12} \bullet=\mu_{13} \bullet$ & & & $H_{0}$ ditolak & $\mu_{12} \bullet \neq \mu_{13} \bullet$ \\
\hline Peme & $\mu_{21} \bullet=\mu_{22} \bullet$ & 3,4 & & $H_{0}$ tidak ditolak & $\mu_{21} \bullet=\mu_{22} \bullet$ \\
\hline & $\mu_{21} \bullet=\mu_{23} \bullet$ & & & $H_{0}$ ditolak & $\mu_{21} \bullet \neq \mu_{23} \bullet$ \\
\hline matematika & $\mu_{22} \bullet=\mu_{23} \cdot$ & 3,2534 & 6,0757 & $H_{0}$ tidak ditolak & $\mu_{22 \bullet}=\mu_{23} \bullet$ \\
\hline
\end{tabular}

Berdasarkan hasil uji komparasi ganda antar baris (Tabel 4) pada variabel pemahaman konsep, untuk $\mu_{11} \bullet=\mu_{12} \bullet, \mu_{11} \bullet=\mu_{13}$, dan $\mu_{12} \bullet=\mu_{13}, F_{o b s}>F_{\alpha}$ maka $H_{0}$ ditolak sehingga jika dilihat dari rerata marginalnya model pembelajaran PBL $(66,10)$ menghasilkan pemahaman konsep yang lebih baik daripada model pembelajaran Jigsaw $(62,84)$ maupun STAD $(58,64)$ serta model pembelajaran Jigsaw $(62,84)$ menghasilkan pemahaman konsep matematika yang lebih baik daripada model pembelajaran STAD $(58,64)$. Hasil ini sejalan dengan hasil penelitian Wijayanto (2010) yang menyatakan model pembelajaran PBL memberikan prestasi belajar yang lebih baik daripada model pembelajaran kooperatif. Tetapi dalam penelitian ini prestasi belajar lebih spesifik pada pemahaman konsep dan model pembelajaran kooperatif tipe Jigsaw dan STAD.

Berdasarkan uji komparasi ganda antar baris (Tabel 4) pada variabel pemecahan masalah, untuk $\mu_{21 \bullet}=\mu_{22 \bullet}$ dan $\mu_{22 \bullet}=\mu_{23 \bullet} F_{o b s}<F_{\alpha}$ maka $H_{0}$ tidak ditolak, sehingga siswa yang diberi model pembelajaran PBL mempunyai pemecahan masalah matematika yang sama baiknya dengan siswa yang diberi model pembelajaran Jigsaw dan siswa yang diberi model pembelajaran Jigsaw mempunyai pemecahan masalah matematika yang sama baiknya dengan dengan siswa yang diberi model pembelajaran STAD. Untuk $\mu_{21 \bullet}=\mu_{23 \bullet} F_{o b s}>F_{\alpha}$ maka $H_{0}$ ditolak, sehingga jika dilihat dari rerata marginalnya model pembelajaran PBL $(66,52)$ menghasilkan pemecahan masalah yang lebih baik daripada model pembelajaran STAD $(59,95)$. Hasil ini sejalan dengan hasil penelitian Wijayanto (2010) yang menyatakan model pembelajaran PBL memberikan prestasi belajar yang lebih baik daripada model pembelajaran kooperatif. Tetapi dalam penelitian ini prestasi belajar lebih spesifik pada pemecahan masalah dan model pembelajaran kooperatif tipe Jigsaw dan STAD.

Perbedaan yang tidak signifikan antara model pembelajaran PBL dan Jigsaw pada pemecahan masalah yang dihasilkan karena keterbatasan peneliti pada pelaksanaan 
model PBL dalam proses belajar mengajar, misalnya kurangnya waktu yang diberikan peneliti kepada siswa untuk melakukan pemecahan masalah sesuai dengan cara mereka masing-masing. Perbedaan yang tidak signifikan antara model pembelajaran Jigsaw dan STAD disebabkan peneliti dalam mempraktekkan model pembelajaran STAD maupun Jigsaw ada kalanya mengalami persamaan perlakuan ketika mengajar dan pemberian kesempatan siswa dalam melakukan pemecahan masalah. Akibatnya pemecahan masalah yang dimiliki siswa yang dikenai kedua model ini tidak jauh berbeda.

Tabel 5. Rangkuman Hasil Uji Komparasi Ganda Antar Kolom

\begin{tabular}{|c|c|c|c|c|c|}
\hline $\begin{array}{l}\text { Variabel } \\
\text { Terikat }\end{array}$ & $H_{0}$ & $F_{o b s}$ & $F_{(0,05 ; 2,215)}$ & Keputusan Uji & Kesimpulan \\
\hline Pemahaman & $\mu_{1 \cdot 1}=\mu_{1 \cdot 2}$ & 55,3383 & 6,0757 & $H_{0}$ ditolak & $\mu_{1 \bullet 1} \neq \mu_{1 \cdot 2}$ \\
\hline konsep & $\mu_{1 \bullet 1}=\mu_{1 \cdot 3}$ & 227,2469 & 6,0757 & $H_{0}$ ditolak & $\mu_{1 \bullet 1} \neq \mu_{1 \bullet 3}$ \\
\hline matematika & $\mu_{1 \cdot 2}=\mu_{1 \bullet 3}$ & 72,2966 & 6,0757 & $H_{0}$ ditolak & $\mu_{1 \cdot 2} \neq \mu_{1 \cdot 3}$ \\
\hline Pemecahan & $\mu_{2 \bullet 1}=\mu_{2 \bullet 2}$ & 25,0905 & 6,0757 & $H_{0}$ ditolak & $\mu_{2 \bullet 1} \neq \mu_{2 \cdot 2}$ \\
\hline masalah & $\mu_{2 \bullet 1}=\mu_{2 \cdot 3}$ & 84,2142 & 6,0757 & $H_{0}$ ditolak & $\mu_{2 \bullet 1} \neq \mu_{2 \cdot 3}$ \\
\hline matematika & $\mu_{2 \cdot 2}=\mu_{2 \cdot 3}$ & 22,1035 & 6,0757 & $H_{0}$ ditolak & $\mu_{2 \cdot 2} \neq \mu_{2 \cdot 3}$ \\
\hline
\end{tabular}

Berdasarkan Tabel 5, uji komparasi ganda antar kolom pada variabel pemahaman konsep tersebut, untuk $\mu_{1 \bullet 1}=\mu_{1 \bullet 2}, \mu_{1 \bullet 1}=\mu_{1 \bullet 3}$ dan $\mu_{1 \bullet 2}=\mu_{1 \bullet 3}, F_{o b s}>F_{\alpha}$ maka $H_{0}$ ditolak, sehingga jika dilihat dari rerata marginalnya siswa dengan AQ tinggi $(71,83)$ mempunyai pemahaman konsep matematika yang lebih baik daripada siswa dengan AQ sedang $(62,78)$ dan rendah $(52,31)$ serta siswa dengan AQ sedang $(62,78)$ mempunyai pemahaman konsep matematika lebih baik daripada siswa dengan AQ rendah (52,31). Hasil ini sejalan dengan hasil penelitian Hawadi. (2002) yang menunjukkan bahwa siswa dengan AQ tinggi dan sedang mampu mengalami peningkatan yang lebih besar dalam pretasi belajar daripada siswa dengan AQ rendah. Tetapi dalam penelitian ini prestasi belajar lebih spesifik pada pemahaman konsep matematika siswa.

Uji komparasi ganda antar kolom ( Tabel 5) pada variabel pemecahan masalah tersebut, untuk $\mu_{2 \bullet 1}=\mu_{2 \bullet 2}, \mu_{2 \bullet 1}=\mu_{2 \bullet 3}$, dan $\mu_{2 \bullet 2}=\mu_{2 \bullet 3}, F_{o b s}>F_{\alpha}$ maka $H_{0}$ ditolak, sehingga jika dilihat dari rerata marginalnya siswa dengan AQ tinggi $(71,76)$ mempunyai pemecahan masalah matematika yang lebih baik daripada siswa dengan AQ sedang $(62,92)$ dan rendah $(54,52)$ serta siswa dengan AQ sedang $(62,92)$ mempunyai pemecahan masalah matematika yang lebih baik daripada siswa AQ rendah $(54,52)$.

Berdasarkan paparan uji ANAVA pada masing-masing variabel terikat, diketahui bahwa pada variabel terikat pemahaman konsep terdapat interaksi antara model pembelajaran dan AQ terhadap pemahaman konsep matematika siswa. Untuk itu perlu dilakukan uji komparasi ganda antar sel pada variabel terikat pemahaman konsep. Sedangkan untuk variabel terikat pemecahan masalah karena tidak terdapat interaksi antara model pembelajaran dan AQ maka tidak dilakukan uji komparasi ganda antar sel. 
Berikut rangkuman hasil uji komparasi rerata antar sel pada baris dan kolom yang sama untuk varibel terikat pemahaman konsep yang disajikan berturut-turut pada Tabel 6 dan Tabel 7.

Tabel 6 Rangkuman Uji Komparasi Ganda Antar Sel Baris yang Sama pada Pemahaman Konsep Matematika

\begin{tabular}{cccccc}
\hline No & $H_{0}$ & $F_{\text {obs }}$ & $F_{(0,05 ; 8 ; 215)}$ & Keputusan Uji & Kesimpulan \\
\hline 1. & $\mu_{111}=\mu_{112}$ & 6,81 & 15,8532 & $H_{0}$ tidak ditolak & $\mu_{11}=\mu_{12}$ \\
2. & $\mu_{111}=\mu_{113}$ & 57,85 & 15,8532 & $H_{0}$ ditolak & $\mu_{11} \neq \mu_{13}$ \\
3. & $\mu_{112}=\mu_{113}$ & 29,64 & 15,8532 & $H_{0}$ ditolak & $\mu_{12} \neq \mu_{13}$ \\
4. & $\mu_{121}=\mu_{122}$ & 13,29 & 15,8532 & $H_{0}$ tidak ditolak & $\mu_{21}=\mu_{22}$ \\
5. & $\mu_{121}=\mu_{123}$ & 53,48 & 15,8532 & $H_{0}$ ditolak & $\mu_{21} \neq \mu_{23}$ \\
6. & $\mu_{122}=\mu_{123}$ & 15,87 & 15,8532 & $H_{0}$ ditolak & $\mu_{22} \neq \mu_{23}$ \\
7. & $\mu_{131}=\mu_{132}$ & 42,46 & 15,8532 & $H_{0}$ ditolak & $\mu_{31} \neq \mu_{32}$ \\
8. & $\mu_{131}=\mu_{133}$ & 120,96 & 15,8532 & $H_{0}$ ditolak & $\mu_{31} \neq \mu_{33}$ \\
9. & $\mu_{132}=\mu_{133}$ & 26,90 & 15,8532 & $H_{0}$ ditolak & $\mu_{32} \neq \mu_{33}$ \\
\hline
\end{tabular}

Uji komparasi ganda antar sel baris yang sama pada variabel pemahaman konsep tersebut, untuk $\mu_{111}=\mu_{112}, F_{o b s}<F_{\alpha}$ maka $H_{0}$ tidak ditolak sehingga siswa yang diberi model pembelajaran PBL dengan AQ tinggi mempunyai pemahaman konsep matematika yang sama baiknya dengan siswa AQ sedang. Sementara untuk $\mu_{111}=\mu_{113}$ dan $\mu_{112}=$ $\mu_{113}, F_{o b s}>F_{\alpha}$ maka $H_{0}$ ditolak sehingga jika dilihat dari rerata marginalnya, siswa yang dikenai model pembelajaran PBL dengan AQ tinggi (73,04) mempunyai pemahaman konsep matematika yang lebih baik daripada siswa dengan AQ rendah $(55,60)$ dan siswa yang dikenai model pembelajaran PBL dengan AQ sedang $(67,59)$ mempunyai pemahaman konsep matematika yang lebih baik daripada AQ rendah $(55,60)$.

Sementara itu untuk $\mu_{121}=\mu_{122}, F_{o b s}<F_{\alpha}$ maka $H_{0}$ tidak ditolak sehingga siswa yang dikenai model pembelajaran Jigsaw dengan AQ tinggi mempunyai pemahaman konsep matematika yang sama baiknya AQ sedang. Sementara untuk $\mu_{121}=\mu_{123}$ dan $\mu_{122}=\mu_{123}, F_{o b s}>F_{\alpha}$ maka $H_{0}$ ditolak sehingga siswa yang dikenai model pembelajaran Jigsaw dengan AQ tinggi $(70,91)$ mempunyai pemahaman konsep matematika yang lebih baik daripada AQ rendah $(54,75)$ dan siswa yang dikenai model pembelajaran Jigsaw dengan AQ sedang $(63,14)$ mempunyai pemahaman konsep matematika yang lebih baik daripada AQ rendah $(54,75)$.

Kemudian untuk $\mu_{131}=\mu_{132}, \quad \mu_{131}=\mu_{133}$ dan $\mu_{132}=\mu_{133}, F_{o b s}>F_{\alpha}$ maka $H_{0}$ ditolak, sehingga siswa yang diberi model pembelajaran STAD dengan AQ tinggi $(71,83)$ mempunyai pemahaman konsep matematika yang lebih baik daripada siswa dengan AQ sedang $(57,80)$ dan rendah $(46,91)$ serta siswa yang dikenai model pembelajaran STAD dengan AQ sedang $(57,80)$ mempunyai pemahaman konsep matematika yang lebih baik daripada siswa dengan AQ rendah $(46,91)$. 
Tabel 7 Rangkuman Uji Komparasi Ganda Antar Sel Kolom yang Sama pada Pemahaman Konsep Matematika

\begin{tabular}{cccccc}
\hline No & $H_{0}$ & $F_{\text {obs }}$ & $F_{(0,05 ; 8 ; 215)}$ & Keputusan Uji & Kesimpulan \\
\hline 1. & $\mu_{111}=\mu_{121}$ & 0,93 & 15,8532 & $H_{0}$ tidak ditolak & $\mu_{11}=\mu_{12}$ \\
2. & $\mu_{111}=\mu_{131}$ & 0,50 & 15,8532 & $H_{0}$ tidak ditolak & $\mu_{11}=\mu_{13}$ \\
3. & $\mu_{121}=\mu_{131}$ & 0,06 & 15,8532 & $H_{0}$ tidak ditolak & $\mu_{12}=\mu_{13}$ \\
4. & $\mu_{112}=\mu_{122}$ & 4,90 & 15,8532 & $H_{0}$ tidak ditolak & $\mu_{21}=\mu_{22}$ \\
5. & $\mu_{112}=\mu_{132}$ & 24,61 & 15,8532 & $H_{0}$ ditolak & $\mu_{21} \neq \mu_{23}$ \\
6. & $\mu_{122}=\mu_{132}$ & 7,21 & 15,8532 & $H_{0}$ tidak ditolak & $\mu_{22}=\mu_{23}$ \\
7. & $\mu_{113}=\mu_{123}$ & 0,14 & 15,8532 & $H_{0}$ tidak ditolak & $\mu_{31}=\mu_{32}$ \\
8. & $\mu_{113}=\mu_{133}$ & 14,07 & 15,8532 & $H_{0}$ tidak ditolak & $\mu_{31}=\mu_{33}$ \\
9. & $\mu_{123}=\mu_{133}$ & 12,57 & 15,8532 & $H_{0}$ tidak ditolak & $\mu_{32}=\mu_{33}$ \\
\hline
\end{tabular}

Uji komparasi ganda antar sel kolom yang sama pada variabel pemahaman konsep tersebut, untuk $\mu_{111}=\mu_{121}, \mu_{111}=\mu_{131}$ dan $\mu_{121}=\mu_{131}, F_{o b s}>F_{\alpha}$ maka $H_{0}$ ditolak, sehingga jika dilihat dari rerata marginalnya, siswa dengan AQ tinggi yang diberi model pembelajaran PBL $(73,04)$ mempunyai pemahaman konsep matematika yang lebih baik daripada Jigsaw $(70,91)$ dan STAD $(71,48)$ serta siswa dengan AQ tinggi yang diberi model pembelajaran Jigsaw $(70,91)$ mempunyai pemahaman konsep matematika yang tidak lebih baik daripada STAD $(71,48)$.

Sementara itu untuk $\mu_{112}=\mu_{122}, F_{o b s}<F_{\alpha}$ maka $H_{0}$ tidak ditolak, sehingga siswa dengan AQ sedang yang diberi model pembelajaran PBL mempunyai pemahaman konsep matematika yang sama baiknya STAD. Sementara untuk $\mu_{112}=\mu_{132}$ dan $\mu_{122}=\mu_{132}, F_{o b s}>F_{\alpha}$ maka $H_{0}$ ditolak, sehingga jika dilihat dari rerata marginalnya, siswa dengan AQ sedang yang dikenai model pembelajaran PBL $(67,59)$ mempunyai pemahaman konsep matematika yang lebih baik daripada Jigsaw $(63,25)$ dan siswa dengan AQ sedang yang dikenai model pembelajaran Jigsaw $(63,25)$ mempunyai pemahaman konsep matematika yang lebih baik daripada $\operatorname{STAD}(57,80)$.

Kemudian untuk $\mu_{113}=\mu_{123}, \mu_{113}=\mu_{123}$ dan $\mu_{123}=\mu_{133}, F_{o b s}>F_{\alpha}$ maka $H_{0}$ ditolak, sehingga jika dilihat dari rerata marginalnya, siswa dengan AQ rendah yang diberi model pembelajaran PBL $(55,60)$ mempunyai pemahaman konsep matematika yang lebih baik daripada Jigsaw $(54,75)$ dan STAD $(46,91)$ serta siswa dengan AQ rendah yang diberi model pembelajaran Jigsaw $(54,75)$ mempunyai pemahaman konsep matematika yang lebih baik daripada $\operatorname{STAD}(46,91)$.

\section{SIMPULAN DAN SARAN}

Berdasarkan hasil analisis data menggunakan MANOVA dan ANAVA, diperoleh kesimpulan sebagai berikut. (1)(a) Siswa yang dikenai model pembelajaran PBL mempunyai pemahaman konsep yang lebih baik daripada siswa yang dikenai model pembelajaran Jigsaw maupun STAD dan siswa yang dikenai dengan model pembelajaran 
Jigsaw mempunyai pemahaman konsep yang lebih baik daripada siswa yang dikenai dengan model pembelajaran STAD. (b) Siswa yang dikenai model pembelajaran PBL mempunyai pemecahan masalah yang sama baiknya dengan siswa yang dikenai model pembelajaran Jigsaw tetapi lebih baik daripada model pembelajaran STAD, dan model pembelajaran Jigsaw mempunyai pemecahan masalah yang sama baiknya dengan siswa yang dikenai model pembelajaran STAD. (2)(a) Siswa dengan AQ tinggi mempunyai pemahaman konsep yang lebih baik daripada siswa yang mempunyai AQ sedang maupun rendah, dan pemahaman konsep siswa dengan AQ sedang lebih baik dari siswa dengan AQ rendah. (b) Siswa dengan AQ tinggi mempunyai pemecahan masalah yang lebih baik daripada siswa dengan AQ sedang maupun rendah, dan siswa dengan AQ sedang mempunyai pemecahan masalah yang lebih baik daripada siswa dengan AQ rendah. (3)(a) Pada masing-masing model pembelajaran, untuk PBL dan Jigsaw, siswa dengan AQ tinggi mempunyai pemahaman konsep yang sama baik dengan siswa AQ sedang tetapi lebih baik daripada siswa dengan AQ rendah, dan pemahaman konsep siswa dengan AQ sedang lebih baik dari siswa dengan AQ rendah sedangkan pada model pembelajaran STAD siswa denagn AQ tinggi mempunyai pemahaman konsep yang lebih baik daripada siswa dengan AQ sedang maupun rendah dan pemahaman konsep siswa dengan AQ sedang lebih baik dari siswa dengan AQ rendah. (b) Pada masing-masing model pembelajaran baik itu model pembelajaran PBL, Jigsaw maupun STAD, siswa yang mempunyai AQ tinggi mempunyai pemecahan masalah yang lebih baik daripada siswa dengan AQ sedang maupun rendah, dan siswa dengan AQ sedang mempunyai pemecahan masalah yang lebih baik daripada siswa dengan AQ rendah. (4)(a) Pada masing-masing kategori AQ, untuk AQ tinggi dan rendah, siswa yang dikenai model pembelajaran PBL, Jigsaw maupun STAD, ketiganya mempunyai pemahaman konsep yang sama baiknya sedangkan siswa dengan AQ sedang yang dikenai dengan model pembelajaran PBL mempunyai pemahaman konsep yang sama baiknya dengan siswa yang dikenai dengan model pembelajaran Jigsaw tetapi lebih baik daripada model pembelajaran STAD sedangkan siswa dengan AQ sedang yang dikenai dengan model pembelajaran PBL mempunyai pemahaman konsep yang sama baiknya dengan siswa yang dikenai dengan model pembelajaran Jigsaw tetapi lebih baik daripada STAD dan siswa dengan AQ sedang yang dikenai dengan model pembelajaran Jigsaw mempunyai pemahaman konsep yang lebih baik daripada STAD. (b) Pada masing-masing AQ, baik AQ tinggi, sedang dan rendah, siswa yang dikenai model pembelajaran PBL mempunyai pemecahan masalah yang sama baiknya dengan siswa yang dikenai model pembelajaran Jigsaw tetapi lebih baik daripada model pembelajaran STAD, dan siswa yang dikenai 
model Jigsaw mempunyai pemecahan masalah yang lebih baik daripada model pembelajaran STAD.

Sesuai simpulan dari penelitian ini, peneliti memberikan saran sebagai berikut. (1) Bagi guru, guru hendaknya dapat memilih model pembelajaran yang tepat untuk meningkatkan kemampuan matematika siswa, baik pemahaman konsep ataupun pemecahan masalah matematika siswa khususnya pada pokok bahasan Turunan Fungsi. Berdasarkan penelitian yang telah dilakukan, model pembelajaran PBL baik untuk meningkatkan kemampuan matematika siswa pada materi Turunan Fungsi khususnya pada pemahaman konsep dan pemecahan masalah matematika. Model lain yang dijadikan alternatif yaitu model pembelajaran Jigsaw. Model ini juga mampu meningkatkan kemampuan matematika siswa pada materi Turunan Fungsi khususnya pada pemahaman konsep dan pemecahan masalah matematika. Sebagai pilihan ketiga apabila guru mengalami kesulitan menggunakan model pembelajaran PBL maupun Jigsaw maka model pembelajaran STAD dapat pula digunakan untuk meningkatkan kemampuan matematika siswa pada materi Turunan Fungsi khususnya pada pemahaman konsep dan pemecahan masalah matematika. Model ini lebih sederhana walaupun hasilnya tidak sebaik jika menggunakan model pembelajaran PBL atau Jigsaw. Selain itu, Model pembelajaran yang diterapkan oleh guru juga diharapkan mampu memberikan perlakuan yang sama sesuai dengan karakteristik siswa, misalnya AQ yang dimiliki oleh siswa. Berdasarkan hasil peneltian ini ternyata AQ siswa mempunyai pengaruh penting untuk kemampuan matematika siswa pada materi Turunan Fungsi khususnya pada pemahaman konsep dan pemecahan masalah matematika. Oleh karena itu ketika membelajarkan materi Turunan Fungsi hendaknya guru memperhatikan AQ siswa. (2) Bagi peneliti selanjutnya, hendaknya dapat melakukan penelitian dengan kajian yang lebih mendalam lagi tentang pemahaman konsep dan pemecahan masalah. Peneliti selanjutnya dapat juga melakukan penelitian dengan model pembelajaran lainnya yang sekiranya sesuai dengan tipe AQ yang dimiliki siswa.

\section{DAFTAR PUSTAKA}

Attle, S. and Baker, B. 2007. Cooperative Learning in a Competitive Environment: Classroom Applications. International Journal of Teaching and Learning in Higher Education, 19 (1), 77-83. http://www.isetl.org/ ijtlhe/pdf/IJTLHE121.pdf. Diakses tanggal 18 Maret 2014.

Chamberlin, S. A., and Moon, S. M. 2008. How Does the Problem Based Learning Approach Compare to the Model-Eliciting Activity Approach in Mathematics?. International Journal for Mathematics Teaching and Learning, Vol. 9 No. 3, 78105. http://www.cimt.plymouth.ac.uk/journal/ chamberlin.pdf. Diakses tanggal 18 Oktober 2014. 
Giganti, P. 2007. Why Teach Problem Solving, Part I: The Worl Needs Good Problem Solvers!. Communicator, Vol.31 No.4.

Kaasila, R. 2009. Finnish Pre-Service Teachers' and Upper Secondary Students' Understanding of Division and Reasoning Strategies Used. Journal of Educational Studies in Mathematics, 73(3), pp 249-250.

Masek, A. 2012. The Effects Of Problem Based Learning On Knowledge Acquisition, Critical Thinking, And Intrinsic Motivation Of Electrical Engineering Students. Malaysia: Faculty of Technical and Vocational Education Tun Hussein University.

NCTM . 2009. Focus in High School Mathematics: Reasoning and Sense Making. http://www.standards.nctm.org/document. Diakses Tanggal 10 November 2014.

Ofodu, G. O. 2009. The Power of Learning Styles: Memacu Anak Meningkatkan Prestasi dengan Mengenal Adversity Quotientnya. Terjemahan Nina Fauziah. Bandung: Kaifa.

Ozkan, B. 2010. Cooperatif Learning Teaching Through Internet Based Education: $A$ Model Proposal, Vol 130,no 3, pp 6-56.

Slavin, R. E. 2005. Cooperative Learning. Bandung: Nusa Media.

Stoltz, P. G. 2000. Adversity Quotient : Mengubah Hambatan menjadi Peluang. Jakarta : Grasindo. 